\title{
LA FORMACIÒN DE LA VOLUNTAD: RETO ACTUAL DE LA PEDAGOGİA
}

Sara Elvira Galbán Lozano

LA GLOBALIZACIÓN HA PROVOCADO CAMBIOS SIGNIFICATIVOS EN LA CONCEPCIÓN de educación, sin embargo, hay cosas que nunca cambiarán como que la educación siempre será tendiente a buscar el desarrollo integral del ser humano. Lo que cambian son sus estrategias y medios y es por eso que ahora ya no importa tanto tener muchos conocimientos o no tenerlos, sino el aprendizaje para el cambio, necesario para adaptarse al continuo avance de la ciencia y la tecnología. Ciertamente el tener solamente conocimientos teóricos, no satisface el ideal de un ser integral, pero tampoco podemos pensar que la teoría ha perdido vigencia y que lo único que vale es el saber hacer.

Es un hecho que hoy más que nunca al hombre se le exige la actualización constante y el dominio de técnicas de trabajo cada vez más sofisticadas. Sin embargo, no podemos olvidar la formación de lo que lo hace ser persona, su inteligencia y su voluntad, ésta última considerada por siglos como el fundamento de toda verdadera educación, y es que eso representa, pues la educación consiste en el paso de un estado a otro más perfecto. Ese paso ha de ser dado, además de inteligente y libremente, con la intervención eficaz de la voluntad.

La voluntad es la facultad del querer, procede del latín voluntas-atis, que significa querer. Es la facultad del hombre para querer algo, lo que implica admitir o rechazar. La voluntad se establece como un acto intencional, de inclinarse o dirigirse hacia algo, e interviene en ella la decisión.

La voluntad es una de las facultades espirituales o superiores del hombre, por la que éste se encuentra capacitado para ten- 
der al bien aprehendido por el entendimiento. Se diferencia del entendimiento porque no es una facultad aprehensiva como éste, sino tendencial, por la que se quiere la realidad que el entendimiento presenta bajo la razón universal de bien. La voluntad se distingue además de los apetitos sensibles, porque aunque éstos sean también tendenciales, como la voluntad, su tendencia sigue al bien aprehendido por los sentidos, mientras que la voluntad sigue al bien aprehendido por el conocimiento intelectual, cuyos bienes son generales y universales y por tanto, es visto bajo la óptica de bienes concretos y particulares ${ }^{1}$.

La voluntad, como potencia del querer o apetito intelectual, genera el acto voluntario, que es aquél que procede de un principio intrínseco con conocimiento del fin. Es de ahí que educar la voluntad, es enseñar a querer inteligentemente. Se constituye como el reto de todo educador, conseguir la intencionalidad del alumno.

Es bien sabido que la inteligencia y la voluntad son la causa material de la educación y de la educabilidad humana, sin embargo, en sí mismas también son objeto de educación.

Por ello nuestros esfuerzos se deberán dirigir hacia la formación de ambas facultades. Específicamente se puede considerar que una persona posee una voluntad formada, o está en camino de su formación, cuando es responsable de las consecuencias de sus actos, de las razones de ellos y de realizar su proyecto de vida.

Una persona con una voluntad formada responde a las siguientes características:

1) Actúa de modo más libre.

2) Actúa por unos fines determinados y cuando no los consigue, vuelve a intentarlo, pues lo que importa es alcanzar la meta.

3) Es capaz de hacer lo que tiene que hacer en cada momento, aunque le cueste.

4) Tiene suficientemente claro lo que quiere. 
5) Trabaja duro para conseguir su objetivo.

6) Sabe lo que persigue y cómo ha de hacerlo.

7) Su fortaleza sobrepasa los límites de la pereza.

8) Es responsable de sus actos y de su propia persona.

En una voluntad formada se distinguen dos dimensiones: la autodeterminación y la intencionalidad. La autodeterminación se refiere a la libertad que se tiene para decidir o determinar cada acción, y la intencionalidad que es la apertura o la dirección de la voluntad hacia su objeto.

Se dice que, una voluntad formada reclama actos voluntarios, cuya principal característica es el proceder de un principio intrínseco con conocimiento del fin ${ }^{2}$.

Y dentro de la formación de la voluntad encontramos cuatro líneas de desarrollo en las que los educadores deben incidir y son: voluntad fuerte, voluntad sana, voluntad libre y voluntad buena.

La voluntad fuerte coincide en gran parte con la educación de la virtud humana de la fortaleza, pues se considera que una voluntad es fuerte cuando la persona ha alcanzado un nivel de fortaleza aceptable y es capaz de afrontar situaciones ambientales perjudiciales, resistiéndose a las influencias nocivas, soportando las molestias y entregándose con valentía en caso de poder influir positivamente. Es capaz de vencer dificultades y de acometer empresas grandes. La labor educativa ha de ayudar a que el educando adquiera y asegure ante las dificultades, la firmeza y constancia, con el fin de adquirir la virtud y cumplir con los objetivos deseados. En el desarrollo de estas dos capacidades: la de resistir y la de acometer radica el logro de una voluntad fuerte.

Si consideramos al bien como el objeto formal de la voluntad, entonces estaremos de acuerdo con que todo aquello que vaya contra el bien enferma a la voluntad, y una voluntad sana consiste precisamente en reconocer el bien. Y algo es bueno, 
cuando beneficia el comportamiento personal, el trato personal y el crecer como persona individual y como miembro de un grupo. Por lo que el tener una voluntad sana no sólo consiste en saber cuando algo está bien o cuando algo está mal, sino en hacer el bien, para que la voluntad no enferme.

La voluntad libre, es una voluntad ejercida a partir de verdaderas decisiones, no atada a dependencias, ni a respetos humanos y mucho menos cegada por una afectividad desbordada. Es en la decisión donde se actualiza la libertad, pero hay que aprender a decidir, y por tanto a pensar, a informarse, a decidir y a realizar lo decidido.

La voluntad buena es la voluntad orientada al bien lo cual supone el fomentar el amor a la verdad y a la rectitud. Lo que conlleva una constante rectificación de la intención y de los motivos.

La formación de la voluntad, juega un papel indispensable en la realización de cualquier obra, temporal o continuada, y es por eso que podemos distinguir tres momentos o períodos: la voluntad inicial, la voluntad continuativa y la voluntad de acabamiento.

* La voluntad inicial se refiere al comienzo del acto pues se requiere de un esfuerzo especial para romper la inercia que opera constantemente en la actividad humana, para comenzar cualquier acción es necesario dejar de hacer lo que se estaba haciendo.

* La voluntad continuativa o perseverante, en donde la voluntad se ha de mantener activa en la constancia del actuar para continuar la obra iniciada, para lo cual hay que mantener activa la inteligencia para no perder el sentido y fin de nuestra actividad. Es la voluntad capaz de superar las frustraciones y volver a empezar.

* La voluntad de acabamiento que supone esfuerzo para terminar bien lo iniciado ${ }^{3}$.

El papel de todo educador consiste en primera instancia en 
hacer que las personas se hagan conscientes de que su voluntad requiere ser formada, y que no hay otra forma de lograrlo más que ejercitándose en ello. En segunda instancia el educador deberá ayudar a la persona a encaminar todos sus esfuerzos hacia la consecución de fines valiosos a través del conocimiento personal y el servicio a los demás.

\section{EL PAPEL DEL CARÁCTER}

Por mucho tiempo los términos de formación del carácter y de la voluntad se han usado como sinónimos y aún en nuestros días así se maneja, pues se consideran ambas como el esfuerzo encaminado a la construcción de una personalidad madura y fuerte. Aunque no es del todo erróneo considerarlo así, es necesario establecer una distinción que nos permita ubicar el ámbito de acción a que se refiere cada uno de los conceptos.

El carácter ha sido un tema ampliamente estudiado no sólo por la filosofía, la psicología y la pedagogía, sino por muchas otras ramas del saber. Sin embargo, nos limitaremos a tratar de definirlo desde estos campos.

Desde un punto de vista ético, y por tanto filosófico, el carácter se entiende como la forma de vida moral elegida por cada persona, en la que resaltan la fidelidad a sí mismo, la firmeza y la directriz unívoca de la vida.

Desde el punto de vista psicológico el carácter se refiere a la manera en que cada persona se enfrenta al mundo que lo rodea, haciéndose diferente de las demás. Generalmente se piensa que el carácter reside en la posesión de un conjunto de atributos, naturales y/o adquiridos, que constituyen el modo de ser y la personalidad. Sin embargo, este pensamiento es muy parcial pues las dotes externas o cualidades naturales no estructuran el carácter, sino sólo las cualidades voluntariamente adquiridas, que llamamos virtudes. El carácter no sólo es el conjunto de atributos sino la actitud que se adopta frente a las diversas circunstancias ${ }^{4}$. 
Pero entonces cabría preguntarse si el carácter es parte integrante de la voluntad o si la engloba. Y la respuesta que hemos encontrado es que el carácter es la cualidad humana gracias a la cual las potencias superiores -inteligencia y voluntad- predominan sobre las potencias inferiores, pudiendo definirlo como una forma de ser y actuar derivada del uso de la inteligencia y de la voluntad por encima de los impulsos sensibles, es la condición humana que se deja conducir por la inteligencia y la voluntad, por lo que la formación del carácter presupone la formación de ambas facultades 5 .

Podemos concluir entonces que sí existen claras diferencias entre lo que se entiende por voluntad y lo que se entiende por carácter. Si lo analizamos desde un punto de vista psicológico entenderemos que el carácter se constituye como la parte modificable de la personalidad. Para la Filosofía, podríamos pensar, que el carácter es el resultado de una personalidad madura en donde la inteligencia y la voluntad dominan todo el actuar humano, al igual que para la Pedagogía en donde la formación del carácter constituye el núcleo de la formación personal. Cabe resaltar que se considera al carácter como una forma de ser mientras que la voluntad es una facultad, podría decirse que la primera está en el campo de las actitudes y la segunda en el campo óntico de la persona.

Después de haber analizado las diferencias entre estos dos términos lo que sí resulta evidente es que tanto la formación de la voluntad como la formación del carácter entran en acción para buscar que la persona sea más dueña de sí misma, de sus capacidades y de todo lo que está dentro de sí, porque autoposeerse implica tener dominio sobre lo que de más suyo se tiene: la riqueza personal.

\section{EDUCACIÓN DE LA VOLUNTAD}

A lo largo de la historia de la humanidad, la educación en sus 
diferentes facetas ha buscado formar mejores hombres. En algunas ocasiones se le ha dado mayor auge al desarrollo de habilidades, o a la adquisición de conocimientos, o tal vez a la modificación de conductas, pero lo que sí es indiscutible es que toda la educación se hace por la voluntad, porque nadie puede educarse sin querer querer. Es en este sentido que se afirma que el educando, bien lo sabemos, es el agente principal de su propia formación.

Sabemos que la educación no debe centrarse en buscar el desarrollo parcial de la persona en una u otra esfera, pensando que es mejor desarrollar habilidades en vez de conocimientos. Por el contrario, a lo que se debe aspirar es a formar personalidades íntegras, hasta donde humanamente es posible. Para ello es indispensable la formación de la voluntad, en cuanto que ésta es la facultad que gobierna toda la vida psíquica, pues la bondad y utilidad de las restantes facultades y capacidades dependerá de cómo sean utilizadas por la voluntad. Además sin la educación de la voluntad no puede darse la formación de la personalidad, pues como capacidad operante de la persona contribuye a modelarla y a configurarla holísticamente.

Si la voluntad no se educa adecuadamente, el comportamiento del hombre queda a expensas de los vaivenes de la impulsividad espontánea y, por tanto puede desajustarse fácilmente. En tal caso se actúa por puro deseo espontáneo e irreflexivo, en lugar de por una voluntad libre, propositiva y finalista. La espontaneidad sin fundamento racional no deviene en libertad sino en capricho.

La voluntad en estado natural, sin la educación queda sin autoconducción posible, pues la persona no se conoce y por tanto no se autodomina ni se autoposee, y sus "actos libres" quedan a merced del instante. En cambio una voluntad formada facilita la reflexión, la intelectualización del acto volitivo y, con ella, el autocontrol personal, pues el dominio de sí mismo libera al hombre, le hace más libre optimizando la razón y las 
posibilidades de su querer. Esto lo hace mejor hombre porque el ser humano es persona precisamente porque tiene dominio voluntario sobre sus actos libres ${ }^{6}$.

La educación de la voluntad cristaliza cuando la persona se habitúa a aceptar y a querer bienes verdaderamente valiosos, que son aquellos que lo hacen ser más persona, aquellos que son buenos para él, y de ahí la importancia de la educación del esfuerzo, que implica la repetición de actos voluntarios para alcanzar la virtud, y una vez alcanzada requiere de su ejercitación. Obviamente es más cómodo y placentero lo inmediato pero para formar la voluntad es necesario tomar en cuenta que el retraso en la satisfacción de lo inmediato va forjando a un hombre más fuerte y con más decisión?

De ahí que el mejor fundamento de la voluntad sea el ejercicio de la virtud, que se ha considerado desde la antigüiedad como una actitud firme que orienta la conducta y regula los sentimientos, mociones, emociones y afectos del hombre para hacerlo más persona. La virtud no consiste propiamente en un acto, ni aún en muchos actos, sino en un estado o condición, un modo de ser del que brota un modo de hacer o de conducirse, hasta convertirse en un modo de vida8. El vicio también se puede convertir en un modo de vida, pero al contrario de la virtud, éste hace que el hombre se vuelva indigno.

\section{¿EDUCAR LA VOLUNTAD HOY?}

Hoy existe el rumor de que la voluntad ha desaparecido, y es que en el posmodernismo el concepto de decisión voluntaria, desaparece en la masificación. El yo y la responsabilidad se diluyen en la opinión de unos cuantos. La identidad personal no está fija, pues la persona tiene diferentes personalidades de acuerdo a la ocasión que se le presente, lo cual provoca una falta de unidad de vida y las tan frecuentes esquizofrenias.

Además el esfuerzo ya no está de moda, y todo lo que supone disciplina se ha desvalorizado en beneficio del culto al de- 
seo y su justificación inmediata. En nuestros días el esfuerzo no tiene razón de ser porque se considera más natural al hombre el satisfacer todas sus necesidades sin ningún tipo de restricción.

Cabría entonces preguntarse, si el esfuerzo realmente tiene razón de ser o si es un invento de unos cuantos pasados de moda.

Esto no es fácil de expresar, pero si partimos de la idea de que la voluntad es una fuerza, una energía del espíritu, que actúa de forma inmediata sobre el entendimiento y la imaginación, y de forma mediata sobre el apetito sensitivo, y si pensamos un poco en esto nos daremos cuenta de que la voluntad, actúa como un ordenador de la personalidad en todos sus aspectos haciendo que el hombre pueda actuar como tal.

Si decimos que la voluntad es una fuerza entonces podemos afirmar que para lograr su formación requerimos del esfuerzo.

De ahí la justificación del esfuerzo, pero en una sociedad como la nuestra, que no toma en cuenta la voluntad es muy difícil poder hablar o convencer a la gente de su valor.

Esto, que trae múltiples consecuencias en lo ordinario, ha dado lugar además a enfermedades de la voluntad cada vez más frecuentes, como la abulia, la astenia, la apatía, la dispersión, el atolondramiento, la ansiedad y la conducta en función del capricho que trae como consecuencia la frustración ante lo inesperado 9 .

En una sociedad donde lo que reina es el permisivismo y tantas otras características negativas -sin pensar que lo positivo ha desaparecido -, y que han dado paso a lo que hoy conocemos como generación $\mathrm{X}$ y hombre light, cuya principal característica es el no saber a donde dirigirse, la formación de la voluntad es una cuestión indispensable dentro de la formación de esta generación que tiene borrado de su vocabulario la palabra esfuerzo y sacrificio.

Además, si consideramos que la voluntad es una de las facul- 
tades específicamente humanas, junto con la inteligencia, sería un error enorme el pensar que ha pasado de moda el formarla, si sabemos que es la formación de la voluntad lo que hace que el hombre crezca haciéndose mejor persona.

La formación de la voluntad es hoy el gran reto de la Pedagogía, esto que resulta tan antiguo como el hombre, hoy cobra un mayor interés y relevancia, si consideramos que los grandes desastres que está viviendo el hombre en todos lo ámbitos son a causa de que el yo se ha despersonalizado y la persona está diluida en una sociedad que lo arrastra sin que él tenga las cualidades necesarias para defenderse.

\section{REFERENCIAS BIBLIOGRÁFICAS}

${ }^{1}$ cfr., Grimaldi, N., La voluntad como creación continua, pág.1; Polaino, A., Dimensiones motivacionales y cognoscitivas de la voluntad, pág. 79; Llano, C., La formación de la inteligencia, la voluntad y el carácter, págs. 75-76; Rojas, E., La conquista de la voluntad, págs. 15-16.

2 cfr., Llano, C., op.cit., págs. 106-107; Otero, O., Educar la voluntad, págs. 1923; Polaino, A., op.cit., págs. 73-74.

${ }^{3}$ cfr., García Hoz, V., La obra bien hecha fundamento de la educación de la voluntad, pág. 96; Rojas, E., op.cit., págs. 23-34.

${ }^{4}$ cfr., Castillo, G., Posibilidades y problemas de la edad juvenil. Un dilema ¿intimidad o frivolidad?, págs. 191-192; Llano, C., op.cit., pág. 143.

${ }^{5}$ cfr., Llano, C., op.cit., págs. 113-114.

${ }^{6}$ cfr., Castillo, G., op.cit., pág. 194; Polaino, A., op.cit., págs. 74-76.

${ }^{7}$ cfr., Otero, O., op.cit., págs. 45 y 49; Rojas, E., op.cit., Págs. 39-43.

${ }^{8}$ cfr., Marina, J., El misterio de la voluntad perdida, págs. 13-14.

${ }^{9}$ cfr., Castillo, G., op.cit., págs. 196-198.

\section{BIBLIOGRAFÍA}

CASTILLO, Gerardo. Posibilidades y problemas de la edad juvenil. Un dilema intimidad o frivolidad?; España: EUNSA, 1991.

GARCÍA HOZ, Víctor. "La obra bien hecha fundamento de la educación de la voluntad" en Dimensiones de la voluntad; Madrid: Dossat, 1988.

GRIMALDI, Nicolás. "La voluntad como creación continua" en Dimensiones de la voluntad; Madrid: Dossat, 1988. 
LLANO, Carlos. La formación de la inteligencia, la voluntad y el carácter; México: Trillas, 1999.

MARINA, José Antonio. El misterio de la voluntad perdida; España: Anagrama, 1998.

OTERO, Oliveros. Educar la voluntad; Madrid: Ediciones Internacionales Universitarias, 1999.

POLAINO, Aquilino. "Dimensiones motivacionales y cognoscitivas de la voluntad" en Dimensiones de la voluntad; Madrid: Dossat, 1988

ROJAS, Enrique. La conquista de la voluntad; España: Temas de Hoy, 1994 